\title{
Las nuevas reglas de la participación del público en la prensa digital. Análisis de siete diarios europeos de referencia
}

\author{
Lluís PASTOR PÉREZ \\ Universitat Oberta de Catalunya \\ lpastor@uoc.edu
}

Recibido: 29/03/2011

Aceptado: 13/09/2011

\begin{abstract}
Resumen
El artículo analiza y compara los cambios que se han producido en los textos publicados como cartas al director en la prensa tradicional y en los mensajes de los lectores publicados en la prensa digital. A partir de este análisis se muestra que las reglas que regían la publicación de cartas se han modificado en los nuevos espacios de participación digital. Las reglas de la identidad, de la relevancia, de la brevedad, de la autoridad, del entretenimiento y de la civilidad han dado paso a otras nuevas reglas: la regla del anonimato, del enfrentamiento, de la "ultrabrevedad" y, en el caso de la prensa digital española, la regla de la descalificación. El análisis se ha realizado en siete diarios europeos: ABC, El País, La Vanguardia, The Guardian, The Times, Le Figaro y Le Monde.
\end{abstract}

Palabras clave: Periodismo, retórica, participación digital, prensa digital, diarios europeos

\section{The New Rules of Audience Participation in Digital Media. Analysis of Seven European Newspapers}

\begin{abstract}
The article analyzes and compares the changes produced in texts such as the op-eds published in traditional press and the messages from readers published in the digital media. Through this analysis it is shown that the rules that applied to the op-eds have been modified in the new areas of digital participation. Such rules as identity, significance, brevity, authority, entertainment and civility have given way to other new rules: anonymity, confrontation, "ultrabrebity" and in the case of the Spanish digital press, the rule of disqualification. The analysis has been carried out in seven European newspapers: $A B C$, El País, La Vanguardia, The Guardian, The Times, Le Figaro and Le Monde.
\end{abstract}

Keywords: Journalism, Rethorics, Digital Participation, Digital Media, European Newspapers

\section{Referencia normalizada}

PASTOR PÉREZ, Lluís (2012): "Las nuevas reglas de la participación del público en la prensa digital. Análisis de siete diarios europeos de referencia". Estudios sobre el mensaje periodístico. Vol. 18, núm. 1, págs.: 193-210. Madrid, Servicio de Publicaciones de la Universidad Complutense.

Sumario: 1. La participación de los lectores en la prensa digital. 2. Las reglas de la participación del público en la prensa tradicional. 2.1. la regla de la identidad. 2.2. La regla de la relevancia. 2.3. La regla de la brevedad. 2.4. La regla de la autoridad. 2.5. La regla del entretenimiento. 2.6. La regla de la civilidad. 3. Marco teórico: retórica y periodismo. 3.1. La retórica de la participación. 3.2. La retórica del diálogo. 3.3. La retórica de la intervención. 3.4. Tipos de cartas y mensajes del público en la prensa. 4. Metodología. 5. Resultados. 6. Discusión: las nuevas reglas de la participación. 7. Referencias bibliográficas.

\section{La participación de los lectores en la prensa digital}

Los medios digitales han multiplicado los espacios de participación del público, a diferencia del estricto control que aplicaban en las tradicionales secciones de cartas al director. Esta nueva relación ha modificado las reglas por las que se regían los perio- 
distas que escogían cartas para ser publicadas en los diarios, porque ahora las reglas las marca el propio público. Este artículo aborda los cambios que se han producido en las reglas de participación de los lectores en los diarios digitales.

Hay que tener en cuenta que esa nueva relación entre prensa digital y participación del público ha sido un de los temas que mayor desarrollo ha tenido en los últimos años en los estudios sobre periodismo (Allan y THORSEN, 2009; BARLOW, 2010; Bergström, 2008; Bowman, 2003; Bruns, 2005; CARPenter, 2008; Deuze, 2009; Deuze, Bruns y Neuberger, 2007; Gillmor, 2004; HaAs, 2010; Lasica, 2002; PAPACHARISSI, 2009; ROSENBERRY y ST. JoHN, 2010; SCHAFFER, 2010; SingER y ASHMAN, 2009; YAROS, 2009)). En esta consideración han entrado desde los estudios de participación en los diarios digitales hasta las iniciativas de periodismo ciudadano. Para centrar la cuestión Joyce NIP (2010) ha propuesto siete modos de conexión de los ciudadanos en la producción de noticias en función del grado de control que los periodistas ejercen sobre los ciudadanos. Esta tipología va de la incorporación del ciudadano al medio hasta las prácticas de periodismo ciudadano al margen de los medios. Entre un tipo y otro, NiP sitúa lo que llama respuesta ciudadana o periodismo interactivo. En este caso, los miembros de la audiencia toman la iniciativa de reaccionar a las noticias publicadas por los periodistas, mediante informaciones o comentarios. Este trabajo muestra los resultados que se han obtenido del análisis de la participación de los ciudadanos en siete diarios europeos: tres españoles (El País, ABC y La Vanguardia), dos ingleses (The Times y The Guardian) y dos franceses (Le Monde y Le Figaro).

Algunos estudios se han centrado en el análisis de este fenómeno en la prensa digital europea, aunque la diversidad de cabeceras y de lenguas dificulta los estudios comparativos. En el caso de las webs de los medios de comunicación, Domingo et al. (2008) realizó un estudio para averiguar qué relevancia tenía el CGU (contenido generado por usuarios) en estos medios de diversos países de Europa y Estados Unidos. Sus conclusiones muestran que los medios de comunicación occidentales interpretan la participación de los usuarios on line fundamentalmente como una oportunidad para que los lectores debatan los acontecimientos presentados por los periódicos digitales. De este modo, los diarios digitales facilitan la participación en muchas de las informaciones que presentan. Esta atomización de la participación en los diarios digitales actuales contrasta con las limitaciones de la interactividad con la audiencia que presentaban hace unos años. El estudio de QuinN y TRENCH (2002) sobre 24 medios de comunicación en cuatro países europeos mostraba que la adopción de servicios interactivos que incitaran o incluyeran a la audiencia era limitada.

En otro estudio centrado en la aportación de los ciudadanos en la edición digital del diario británico The Guardian, y realizado a partir de 33 entrevistas con periodistas de la edición impresa y digital de The Guardian, los 15 periodistas que identificaron temas clave relacionados con el CGU centraron los valores sobre la credibilidad y la civilidad -y en su potencial para degradar el periodismo en caso de su ausencia (SINGER Y ASHMAN, 2009).

DESLANDES, FonNET y GODBERT han analizado el fenómeno en la prensa francesa (2009) y se han centrado en los cambios jurídicos y editoriales como consecuencia de 
la participación del público en los medios y de las iniciativas de periodismo ciudadano. Otros estudios sobre la participación del público se han centrado en áreas geográficas más limitadas, como el realizado por RuIz et al (2010) en siete diarios catalanes. Y PALACIOS (2010) ha mostrado cómo la participación de los lectores en las noticias se convierte en una estrategia para generar anclajes locales y mostrar diversidad en los diarios digitales brasileños.

También se constata una proliferación de la voz del público con carácter reactivo y no propiamente como creador de nuevo contenido periodístico. La participación de los ciudadanos habitualmente responde a textos realizados por periodistas (GILLMOR, 2004; LASICA 2002; MATHESON, 2004). Y cuando el ciudadano genera un nuevo contenido periodístico, suelen ser sólo imágenes o vídeos. Respecto a la respuesta de los ciudadanos a textos de los periodistas, FrIEDLAND (2010) afirma que los debates que surgen a partir de los mensajes del público en los periódicos digitales generan discusiones de baja calidad. BERSTROM (2008) añade que en los medios sólo participa una minoría de personas. Incluso el comentario de las noticias y de los artículos publicados por los diarios digitales, que comprende la mayoría de la participación de la gente, suele ser una práctica que, respecto al volumen de la audiencia, suele ser minoritaria.

Por otro lado, FORTUNATI analizó la influencia de internet en la relación entre los lectores y los periodistas de la prensa europea a partir de una encuesta a 239 periodistas de 40 diarios digitales de Chipre, Eslovenia, España, Estonia, Finlandia, Grecia, Italia, Lituania, Reino Unido y Suecia (ForTUNATI et al., 2009). Sólo el 25\% de los participantes en la encuesta manifestaron que tenían acceso detallado a la información sobre los lectores. En este sentido se puso en evidencia que los periodistas bálticos son los que reciben mayor información del comportamiento de sus audiencias. De todos modos, el estudio mostró que no hay una comunicación suficiente para que los periodistas sepan qué interesa a su público.

\section{Las reglas de la participación del público en la prensa tradicional}

Tradicionalmente las publicaciones que incorporan cartas de los lectores entre sus páginas han requerido y requieren una serie de compromisos de los participantes. Estos compromisos se puede resumir en seis reglas: identidad, relevancia, brevedad, autoridad, entretenimiento y civilidad (PASTOR, 2010).

\subsection{La regla de la identidad}

El medio, para publicar una carta, debe tener constancia de su autor. Además el autor debe admitir cualquier tipo de edición sobre su texto. (MoRÁN, 1988; ABril 1999; ARMAÑANZAS, 1996; FoIX, 1997). En esto consiste la regla de la identidad. KAPOOR (1995), en sus estudios sobre los criterios de selección de las cartas al director, apunta que el anonimato en las cartas es el primer motivo de rechazo de una carta por parte de la redacción: el 93,9\% de las cartas anónimas son rechazadas.

\subsection{La regla de la relevancia}

La regla de la relevancia pone de manifiesto el poder del director del diario o del responsable de la selección de las cartas para guiar los contenidos de la sección, orien- 
tar las aportaciones y decantar los debates que se desarrollan entre los lectores. Evidentemente, si se utiliza la sección en beneficio del propio medio puede suceder lo que cuenta WAHL-JORGENSEN (2002): que en el centro no se encuentren las necesidades de la comunidad a la que va dirigido el medio, sino las necesidades del propio medio.

Sobre qué consideran relevante los directores, los estudios no acaban de ponerse de acuerdo. La orientación que se le dé a la sección tiene que ver, pero también el alcance geográfico, si una publicación trata cuestiones generales, como un diario, y por tanto va dirigida a un público amplio, o si es un tipo de publicación especializada y se dirige a públicos segmentados. Tanto es así que, mientras Gomis (1991) afirma que los asuntos tratados en la sección de las cartas al director no suelen coincidir con los reflejados en las portadas de los diarios, WAHL-JORGENSEN (2002) defiende lo contrario, y concluye que la regla de relevancia permite que sea el medio y no el público quien decida sobre los términos del debate social.

\subsection{La regla de la brevedad}

La brevedad es un elemento constitutivo de las cartas. KAPOOR (1995) concluye que más de un tercio de los diarios analizados (exactamente un 35,1\%) limitan la longitud de las cartas a menos de 250 palabras. Menos de la mitad (un 40,5\%) limitan la carta de 251 a 500 palabras. Sólo un 2,4\% permite cartas de hasta 1.000 palabras. El resto, un 15,5\%, no obliga a limitar las cartas. En los estudios anteriores realizados por el mismo KAPOOR el número de diarios que no limitaban la longitud de las cartas ascendía al 33,3\%. HyNDS (1976) había indicado con anterioridad que el 61\% por los diarios limitan la longitud de las cartas y que, entre los diarios que las limitan, el $62 \%$ restringen la longitud a 250 o 300 palabras. Habitualmente, los diarios recortan las cartas que exceden las palabras permitidas (ABRIL, 1999); en cambio, las revistas suelen publicar las cartas en toda su extensión. WAHL-JORGENSEN (2002) pone en relación la brevedad con la relevancia y afirma que la longitud impuesta por los medios para las cartas limita gravemente la posibilidad de desarrollar argumentos en profundidad y debates de interés para la comunidad.

\subsection{La regla de la autoridad}

Las palabras valen más o menos en función de quién sea su dueño. Este es un principio de cualquier debate público. La sección de cartas al director promueve participaciones y debates públicos que acogen a un gran número de personas. No obstante, el hecho mismo de que la firma tenga mucha importancia (tanta que el medio la verifica) suele privilegiar las cartas escritas por personas con trascendencia pública (WAHLJoRgENSEn, 2002). Este hecho lo corrobora el estudio de PASTOR (2010) que muestra que las cartas firmadas por responsables de instituciones representan el $11 \%$ de las cartas publicadas pero constituyen el $42 \%$ de las cartas destacadas gráficamente por el medio.

Pero los directores y los responsables de la sección también están atentos a que los centros irradiadores de poder no debiliten la sección. El responsable de la sección procura ser el único guía de los contenidos de la sección de cartas y que la sección no caiga en manos de partidos, asociaciones u otros grupos de presión (GoMIS, 1991b). 
La sección de cartas, sin embargo, está habitada en su mayoría por firmas anónimas: "intrusos informados", según CLARK (1990).

\subsection{La regla del entretenimiento}

La regla del entretenimiento tiene relación, en algunos casos, con la brevedad; en otros, con la facilidad de expresión. Y en todos con la adecuación de la sección de cartas al público al que se dirige. Pero más allá de la facilidad de la lectura, ¿dónde radica el entretenimiento que proveen las cartas? Las cartas son entretenimiento para quien las lee. Para la persona que la ha escrito su carta suele ser un asunto muy serio. Esta seriedad que impulsa a un ciudadano a escribir una carta llama la atención. Al público le atrae la verdad y la seriedad de esta aportación. El público se convierte en voyeur que disfruta de estas apariciones de otras personas que también son público. Quienes escriben cartas no son profesionales y se produce entre el público un efecto espejo mediante el cual el lector del diario se siente identificado con quien escribe la carta para asentir o para disentir (PASTOR, 2010).

\subsection{La regla de la civilidad}

En cualquier debate, la civilidad es un requisito previo. Enviada ya la carta y leída por el responsable de la sección, la civilidad guía la selección. Es lo que ABRIL (1999) llama la ley de las tres " $i$ ": no se publican las cartas inoportunas, improcedentes e indiscretas. Gomis (1989) habla de buen gusto. Y lo define, en el caso de las cartas, como un texto carente de desafueros ni vulgaridades (1996). HyNDS (1991) amplía el alcance de la regla de la civilidad no sólo al buen gusto, sino también a la exclusión de polémicas religiosas. DUPRE (2000) indica que las cartas difamatorias e insultantes son eliminadas.

Resulta necesaria esta regla de la civilidad para ayudar al buen desarrollo del debate público y para que las participaciones de los lectores sean siempre productivas. Y esta regla se basa en el rechazo de la ofensa y en el manejo de los argumentos y de las emociones para decir o apuntar todo lo que se crea necesario sin quebrar el diálogo.

\section{Marco teórico: retórica y periodismo}

Este método parte inicialmente de las orientaciones teóricas proporcionadas por Gomis (1989, 1991a). En su artículo "Persuadir la gent de que passen coses interessants", Lorenzo Gomis (1994) escribe sobre las formas retóricas de la persuasión periodística, es decir sobre los distintos recursos estratégicos utilizados por los medios para lograr el éxito en la comunicación con el público. Propone Gomis seis tipos distintos de recursos retóricos, algunos de ellos ya avanzados en su Teoría del periodismo (1991b). Las formas retóricas descritas por GomIs son la retórica de la certeza, la retórica de la alarma, la retórica de la personificación, la retórica del presente, la retórica del diálogo y la retórica de la participación. Todos los recursos que utilizan los periodistas en sus textos y en la composición de las distintas páginas de un diario o revista se sintetizan en esta media docena de recursos.

El análisis de la participación del público en los medios de comunicación toma en consideración tres propuestas retóricas: la de la participación, la del diálogo y una que 
no estaba contemplada por la teoría de Gomis, pero que ya he avanzado en trabajos previos, que es la retórica de la intervención.

\subsection{La retórica de la participación}

Para persuadir de que pasan cosas y de que estas cosas que pasan son de nuestro interés, los medios se valen del recurso de la participación. Si de alguna manera nos sentimos reflejados en el medio o, directamente, nos incorporamos a él es muy probable que aumente nuestro grado de interés. Los medios de comunicación también facilitan un canal -que en la prensa en papel no ha sido excesivamente caudaloso- para que las personas que forman parte del público al que se dirige el medio puedan participar de manera directa. Las cartas al director suponen una de las vías primeras y más claras de este recurso de la participación y, en la prensa digital, múltiples son los espacios que recogen la voz de los lectores.

La retórica de la participación recoge las aportaciones que realizan personas que forman el público de un medio en las que informan sobre algo u opinan sobre algo o sobre alguien (KAPOOR, 1992; GOMIS, 1989).

\subsection{La retórica del diálogo}

Los medios yuxtaponen y confrontan hechos para facilitar el diálogo. Los medios fragmentan los mensajes de las personas que opinan públicamente y parece que asistamos a un diálogo entre ellos. En eso consiste el recurso del diálogo en los medios de comunicación. Las cartas al director o los mensajes enviados a la web de un diario abundan en este recurso cuando un lector hace referencia a otra carta o mensaje enviados con anterioridad por otro lector.

En las secciones de cartas de los lectores que publican los periódicos o en los espacios de participación de los diarios digitales encontramos cartas y mensajes que son respuesta de otras cartas o mensajes que se publicaron con anterioridad.

En los espacios de participación de la prensa digital la mediación del director, función básica de selección en la sección de cartas al director, desaparece y los mensajes que responden a mensajes anteriores se suceden. Sólo en los casos en los que se transgreden ciertas normas básicas el criterio del moderador del espacio (un periodista del diario) u otro lector que denuncia esta práctica pueden mediar e impedir que un mensaje llegue a ser leído por el público.

El diálogo entre lectores, el intercambio de ideas entre ciudadanos que se interpelan y que siguen el hilo de sus argumentaciones, genera opinión pública. La figura del director del diario o la tecnología igualan las oportunidades.

\subsection{La retórica de la intervención}

La retórica de la participación recoge las intervenciones de los lectores que aportan informaciones u opiniones sobre el amplio abanico de temas que les preocupan. La retórica del diálogo presenta como diálogo las cartas o mensajes que tienen por interlocutor a otro lector que escribió con anterioridad una carta o mensaje.

La retórica de la intervención es una mezcla de los recursos anteriores. Las cartas que responden a una retórica de la intervención son cartas que, por una parte, partici- 
pan con sus informaciones y opiniones sobre el medio y, por otra, inician y fomentan un diálogo con el propio medio. La retórica de la intervención supone que la participación de los lectores no versará sobre cualquier asunto que pueda interesar al resto del público, sino que la aportación se centra exclusivamente en aspectos que tienen que ver con el propio medio: con su línea editorial; con sus colaboradores -por tanto, los lectores entrarán a valorar y a corregir los textos que aquellos hayan producido- y con cualquier aspecto en el que se vea implicada la publicación, por menor y anecdótico que parezca. Diversos autores han hecho referencia a esta función. (MORÁn, 1988; Gomis, 1989; Nord, 1995; ARMAÑANZAS, 1996; THORNTON, 1996 y 1998; NEMETH y SANDERS, 1999)

\subsection{Tipos de cartas y mensajes del público en la prensa}

Aunque desde los estudios españoles sobre periodismo se han elaborado diversas tipologías, la mayoría de ellas de carácter descriptivo (SANTAMARíA, 1990; ABriL, 1999; ARMAÑANZAS, 1996; MoRÁn, 1988; Del Hoyo, 2001; Gomis, 1991a), propongo una tipología basada en los usos retóricos del periodismo. Las cartas al director y los mensajes en los diarios digitales se pueden agrupar en cartas y mensajes de participación, en cartas y mensajes de diálogo y en cartas y mensajes de intervención, atendiendo al recurso retórico utilizado para hacerlas llegar al público.

Las cartas y los mensajes de participación pueden aportar información u opinión sobre cualquier realidad que importe a la comunidad a la que va dirigida. Tanto si se trata de información como si se trata de opinión distingo entre un redactor con carácter personal o con carácter institucional (en representación de una institución). En caso de que exponga una opinión resulta fundamental distinguir las que opinan a favor de algo de las que critican un acontecimiento o una persona.

Las cartas y los mensajes de diálogo son textos que responden a una carta o mensaje anteriores. Se trata de cartas que canalizan la opinión del lector respecto a otro lector. Este tipo de cartas también pueden estar firmadas con carácter personal o institucional. En este caso, las cartas se mueven en la dicotomía acuerdo-desacuerdo. Resulta esclarecedor establecer los argumentos y, sobre todo, la actitud que muestra el lector respecto a la carta a la que responde. En este sentido, propongo de más acuerdo a más desacuerdo la siguiente escala: ayuda, apoyo, refuerzo de una opinión afín, resolución de conflictos, aclaración, disconformidad y descalificación.

Finalmente, las cartas y mensajes de intervención son textos que pueden aportar información, pero que, fundamentalmente, tienen una fuerte carga de opinión sobre el medio.

\section{Metodología}

Para conocer cómo han cambiado las reglas de la participación del público en la prensa digital se tomó como referencia mi estudio anterior sobre las cartas al director (PASTOR, 2010). En este estudio se escogieron ocho cabeceras de diarios para realizar el análisis. La elección de las cabeceras se guió por el criterio de incluir sólo diarios "de calidad" y se apoyó en las listas que en 1968 y en 1999 elaboró el profesor John C. MerRiLl (1999). 
La selección de diarios para el análisis de las cartas al director incluyó un diario estadounidense, The New York Times; dos diarios ingleses, The Times y The Guardian; dos diarios franceses, Le Monde y Le Figaro, y tres diarios españoles, El País (edición nacional), $A B C$ (edición nacional) y La Vanguardia. La selección cruzó también el criterio de la calidad, destilado por las listas de MerRiLl, con el criterio de variedad ideológica. Para realizar el estudio de los mensajes enviados a los diarios digitales sólo se excluyó el diario The New York Times, con el propósito de centrarse exclusivamente en la prensa europea.

El trabajo de análisis sobre la sección de cartas al director en cada uno de los diarios incluyó un periodo de una semana del mes de febrero de los años 1982 y 2002. Para el análisis de los mensajes publicados en la prensa digital también se ha analizado una semana (siete días) del mes de febrero, del 22 al 28, pero en este caso del año 2010. Para que el volumen de mensajes analizados fuera significativo pero constituyera un corpus similar al del estudio pretérito se analizaron cuantitativamente los cinco temas más participados de la portada de los diarios digitales y se analizaron cualitativamente los 50 últimos mensajes de cada uno de los tres temas más participados cada día en cada uno de los diarios digitales. Si en su momento se analizaron 761 cartas al director, en este estudio se he hecho un análisis cualitativo de 2.117 mensajes de lectores en la prensa digital. Para poder establecer volúmenes de participación por diario se ha complementado este análisis cualitativo con otro de carácter cuantitativo sobre 23.271 mensajes.

Para el análisis de los mensajes se determinó que sólo se analizarían los mensajes vinculados a noticias y no a artículos de opinión y otros espacios de participación. Se ha querido analizar, de este modo, la aparición del público vinculado a los elementos informativos de un diario. Otros estudios podrían hacerse sobre otros espacios de participación que los diarios digitales ponen a disposición de sus lectores. Hay que tener en cuenta que, a diferencia del diario en su versión clásica en papel, el diario digital ha atomizado las posibilidades de participación y las ha multiplicado. Mientras que la prensa clásica defendía que no se podía perder dinero gastando papel para reproducir las aportaciones de los lectores (ARIAS, 1996), la prensa digital se basa en el principio de "se puede hacer tecnológicamente, pues hagámoslo". En concreto, además, se ha analizado la participación de los lectores respecto a las noticias que aparecían en la portada de los diarios digitales. Se entiende portada en un diario digital como la página de inicio y a lo largo de toda su extensión -scrolling-, exceptuando los reportajes especiales y otros elementos informativos que no son fruto de la novedad informativa de las últimas horas (ARMENTIA et al., 2000; SALAVERRÍA, 1997). También se descarta el análisis de las informaciones contenidas en epígrafes como "lo más comentado" puesto que la periodicidad del cambio es desigual en los distintos diarios y alcanza periodos mayores a las 24 horas. El estudio recogió las aportaciones entre las 23.00 y las 24.00 , hora local para cada uno de los países (España, Francia y Reino Unido). Se entendió que de este modo se permitía que hubiera un mayor número de aportaciones. No obstante, no se escapa al investigador el carácter "líquido" (BAUMAN, 2000) y cambiante de las portadas de los diarios digitales en función de la información que se va produciendo, lo que también los distingue de la solidez y estatismo de una portada de diario en su versión impresa. 
Para realizar el análisis cualitativo de los mensajes del público en la prensa digital el método de trabajo y el ámbito de conocimiento del que se han extraído las herramientas de análisis han sido los mismos que se aplicaron al estudio de las cartas al director: el análisis de discurso y la lingüística textual. En concreto el análisis se ha basado en tres conceptos que han permitido estructurar el contenido de cada uno de los mensajes en las categorías anteriormente explicadas (retórica de participación, retórica de diálogo y retórica de intervención). Los conceptos analizados han sido el tema de cada mensaje (VAN DIJK, 1983 y 1995; KAYSER, 1985; BROwn y Yule, 1993; NúÑEz, 1993; CassanY, 1993; Serafini, 1994; Garrido Medina, 1997; Guillén, 1998), la tesis del mensaje (SERAFInI, 1994) y la actitud proyectada (Fraisse \& MeILI: 1967; Buceta: 1992; De Beaugrande y Dressler, 1997)

\section{Resultados}

Los resultados obtenidos de la investigación permiten analizar cuáles han sido los cambios que se han producido en la reglas de participación de los lectores en la prensa digital. Mientras que en la sección de cartas se aplica un riguroso control sobre la identidad del remitente, los mensajes enviados a los diarios digitales pueden ser anónimos. De hecho, parece que lo son en la mayoría de casos. Los sistemas de participación de los diarios digitales, que facilitan el anonimato mediante la firma de los mensajes con nombres inventados (nicks), impide el estudio de las variables personales de los autores de los mensajes. De hecho los trabajos que han procurado inferir una identidad escondida tras el apodo o nick no han llegado a conclusiones determinantes y han tendido a definir el nick como una máscara opaca o como un filtro translúcido respecto a la identidad de quien lo usa (YUS, 2010). De este modo, el perfil que impera en los participantes de la sección de cartas al director, un perfil avalado por diferentes estudios (PASTOR, 2010), y que indica que los escritores de cartas al director son hombres, de edad media y con una educación media o superior es inverificable a partir del análisis de los mensajes enviados en los diarios digitales. Lo que sí que ha dejado de producirse, como consecuencia de este efecto de anonimato (en el análisis no se ha detectado ningún caso), es la presencia de mensajes institucionales. Hay que recordar que las cartas institucionales representaban el $11 \%$ de las cartas publicadas pero que se convertían en el $42 \%$ de las cartas destacadas gráficamente por los diarios (PASTOR, 2010).

Aunque los nicks no permiten identificar a la persona que envía un mensaje a un diario digital, sí que se han detectado diferencias en su uso en los distintos diarios analizados. En el diario The Times el 93\% de los mensajes su responsable firma con un nombre y un apellido o un nombre y la inicial de un apellido. No resulta prueba de nada (el diario no verifica la identidad del autor). Es posible que los nombres y los apellidos indicados no sean los reales, pero también es posible que lo sean y, de este modo, la responsabilidad sobre lo dicho es mayor. El caso de The Times resulta realmente poco frecuente, de todos modos. El siguiente diario que más mensajes muestra firmados con nombres y apellidos es Le Monde ( $41 \%$ de los mensajes). Lo siguen $L e$ Figaro (25\% de los mensajes firmados con nombres posibles), El Pais (16,5\%) y The Guardian (13\%). 
En el caso de los diarios españoles La Vanguardia y $A B C$ el porcentaje de mensajes firmados con nombre y apellido resulta anormalmente bajo respecto al resto de periódicos analizados: en La Vanguardia suponen el 7,5\% del total y en $A B C$ sólo ascienden al 4\% del total. Así mientras en The Times resulta normal encontrar mensajes firmados por Nick Turner, Amelie Smith o Gordon Alexander, o incluso por Marb B. o Ian K. En La Vanguardia y ABC lo normal (más del 94\% de media en ambos diarios) es que los mensajes vengan firmados por Francisco, por Para ex -one, por Yo, por Veterano o por ThePiperOfTheLlobregat.

Estos resultados muestran unas diferencias más cercanas a la diferencias culturales (entre prensa inglesa y francesa, por un lado, y prensa española, por otro) que a los patrones comunes para los redactores de mensajes en los diarios digitales. Diversos autores han propuesto, en este sentido, perfiles sobre los ciudadanos creadores de contenido en la red. BERGSTRÖM (2008) apunta que sólo son una minoría los ciudadanos que participan en las web de noticias, que participan para entretenerse y parece que son las personas con una formación baja o media las que valoran más que las noticias puedan comentarse. Sobre el género no hay conclusiones claras y los estudios suelen apoyarse en los análisis de audiencias en Internet más que en el conocimiento de qué genero (masculino o femenino) participa más en los medios de comunicación. Sobre la edad, BERGSTRÖM (2008) apunta que los jóvenes son más activos.

Lo que sí se detecta en cualquiera de los diarios analizados es una tendencia que consiste en la aparición de ciertos nombres de usuarios de manera reiterada, que se comportan como un grupo aventajado de opinión y que se convierten en una elite.

También se ha analizado la agrupación temática de las informaciones que mayor número de aportaciones del público reciben para comprobar las diferencias que se producen respecto a la sección de cartas al director, en la que los responsables del medio pueden controlar la participación aplicando la regla de la relevancia. En mi estudio anterior de las cartas al director (PASTOR, 2006), las cartas que trataban los temas propios de la sección de Sociedad ocupaban en todos los casos la primera posición, excepto en el caso del diario Le Figaro. En segundo lugar, había una coincidencia mayoritaria por temas de la sección de Internacional y en tercer lugar aparecían temas propios de la sección de Política. Sociedad, Internacional y Política eran las secciones a las que remitían la mayoría de cartas publicadas. Este perfil se completaba con cartas que remitían a las secciones de Economía y de Cultura.

En el caso del análisis de las aportaciones en la prensa digital se modifican estos patrones y los resultados resultan más heterogéneos. Cuatro diarios sitúan los temas de la sección de Política como los que más participaciones reciben: El País $(47,62 \%)$, La Vanguardia (47,62\%), ABC (42,86\%), y el francés Le Figaro $(38,10 \%)$. En cambio The Guardian y Le Monde reciben más participaciones para temas de la sección de Economía (42,86\% en The Guardian y 33,33\% en Le Monde) y The Times, para temas de la sección de Internacional $(38,89 \%)$.

The Times y The Guardian sitúan en segundo lugar los temas de la sección de Política (27,78\% en The Times y 19,05\% en The Guardian). Le Figaro, Le Monde y La Vanguardia sitúan en segundo lugar los temas de la sección de Sociedad $(33,33 \%$ en Le Figaro y en Le Monde, y 23,81\% en La Vanguardia). Y El País y ABC sitúan en segundo lugar los temas de la sección de Internacional (un 28,57\% en ambos casos). 
Resulta significativo comprobar el reducido número de mensajes que reciben los diarios españoles correspondientes a temas económicos, mientras que los temas de esta sección reciben un número significativo de aportaciones en otros diarios europeos: en Le Monde y The Guardian son los temas con más aportaciones y en Le Figaro suponen la tercera sección que mayor interés de participar despierta (19,05\%).

Por otra parte, este análisis no puede corroborar las afirmaciones de MARTIN (2008) según las cuales las malas noticias son buenas noticias para la participación. MARTIN hace esta propuesta a la luz de la capacidad reguladora de los medios sobre la participación de los ciudadanos tratando los temas de la agenda con mayor o menor acritud. En el repaso de la noticia que más participación provocó de cada uno de los diarios durante la semana de análisis no parece que para provocar participación los noticias tengan que ser muy negativas. Los resultados que se han obtenido muestran que la participación depende más de los propios temas de la agenda, los que en cada comunidad (entendida como espacio geográfico y también como grupo vinculado a un medio), pueden ser más conflictivos que en la propia gravedad de las noticias. Así para el diario El País la noticia más comentada durante la semana del 22 al 28 de febrero trataba de una declaraciones de los obispos conforme no iban a excomulgar al rey de España por firmar la ley del aborto; para $A B C$ se trataba de la captura de un etarra; para La Vanguardia, de las consultas independentistas en Cataluña; para Le Monde, de un asunto de política francesa; para Le Figaro, de la decisión de Total de no desmantelar más refinerías en Francia; para The Times, de decisiones sobre política económica británica y para The Guardian, de las elecciones en Gran Bretaña.

Para el análisis de los resultados vinculados con la regla de la brevedad me remito al análisis de la cuota de voz que realicé en mi estudio sobre la sección de cartas al director. Llamé cuota de voz (PASTOR, 2010) a la longitud de las cartas publicadas por los diarios. Los resultados que se obtuvieron indicaban que la media de palabras por carta de los diarios analizados (ABC, El Pais, La Vanguardia, Le Figaro, Le Monde, The Guardian, The Times y The New York Times) era de 157 palabras. El diario que publicaba cartas más breves era el rotativo inglés The Guardian (75 palabras) y el diario que publicaba cartas más largas era el español $A B C$ con 200 palabras por carta de media. De hecho, los diarios españoles se agrupaban en la franja de cartas largas ( $L a$ Vanguardia, 163 palabras por carta; El País, 190 palabras por carta). El diario inglés The Times (146 palabras por carta) y los diarios franceses (Le Monde, 157 palabras; Le Figaro, 158 palabras) se situaban en la franja media.

En cambio en la prensa digital se produce un cambio significativo en la longitud de los mensajes publicados por el público. En primer lugar, y con carácter general, los mensajes son más breves que las cartas que se publican en la sección de cartas al director. La media de palabras por mensaje de los diarios analizados es de 57 palabras. Estas 57 palabras de media suponen una reducción del 67\% respecto a la longitud de las cartas. El público hace textos cuya longitud corresponde a un tercio de la longitud $(36,3 \%)$ de los textos que aparecían publicados en la sección de cartas.

En el análisis diario a diario aparecen otros comportamientos de interés. Los diarios que reproducen mensajes más largos son los diarios ingleses. De hecho, la media de palabras de los mensajes de la versión digital del diario The Guardian es la misma 
que la media de los mensajes editados que aparecían en la sección de cartas al director: 75 palabras por mensaje. En segundo lugar, por orden de longitud de los mensajes se hallan el diario inglés The Times (66 palabras) y el español El País (65). En la zona templada, con una media de palabras por mensaje de entre 50 y 60 palabras, se encuentran los diarios franceses: los mensajes de Le Figaro alcanzan una media de 59 palabras y los mensajes del diario Le Monde, una media de 54 palabras. Y los diarios españoles $A B C$ y La Vanguardia son los que tienen mensajes de los lectores de menor longitud. En ambos casos la media es de 41 palabras por mensaje.

Si se toma una cierta distancia histórica, la disminución de la longitud de los textos que envía el público a los diarios analizados aún cobra mayor relevancia, puesto que el análisis de la longitud de las cartas al director publicadas por estos mismos diarios en 1982 muestra que eran todavía más largas que las que los mismos medios publicaban en 2002 (PASTOR, 2010).

El análisis de los contenidos de los mensajes permite obtener resultados que se pueden vincular con la regla del entretenimiento. Los resultados que se han obtenido al distinguir los mensajes enviados por los lectores que responden a una retórica de la participación (mensajes que informan o que opinan favorable o desfavorablemente acerca de un tema), a una retórica del diálogo (mensajes que responden a otro lector y que muestran su acuerdo o su desacuerdo con él) y a una retórica de la intervención (mensajes que opinan a favor o en contra del medio, de un artículo o de un aspecto concreto) son los siguientes. Los mensajes que se envían responden mayoritariamente en todos los diarios a una retórica de la participación. Se trata de mensajes que aportan opiniones acerca de la actualidad. Este tipo de mensajes representan entre un $67,34 \%$ y un $90,48 \%$ de los mensajes enviados. Los extremos, estos $67,34 \%$ y $90,48 \%$, los marcan el diario español $A B C$ y el diario francés Le Monde, respectivamente. Para el resto de diarios los mensajes que responden a una retórica de la participación suponen el 69,30\% (The Guardian), el 69,43\% (La Vanguardia), el 75,43\% (El País), el 75,90\% (The Times) y el 76,57\% (Le Figaro). Entre estos mensajes que responden a una retórica de la participación, las opiniones negativas son mayoría: el 64,36\%.

El análisis de los mensajes que responden a una retórica de diálogo permite analizar qué cambios se han producido acerca de la regla de la civilidad. Este análisis permite agrupar los diarios analizados en tres bloques. Los diarios cuyos mensajes de diálogo se sitúan alrededor del 30\% de los mensajes, los diarios que se mueven en unas cifras algo inferiores, sobre el $23 \%$, y los diarios que muestran cifras residuales de mensajes de diálogo. Los diarios que se sitúan en el primer bloque, el de mayor diálogo, son los diarios $A B C$ (31,79\% de mensajes de diálogo), La Vanguardia (30\% de mensajes de diálogo) y The Guardian $(29,18 \%$ de mensajes de diálogo). En el segundo bloque, el bloque intermedio se sitúan El País, The Times y Le Figaro con unos porcentajes de mensajes de diálogos del $23,71 \%$, del $23 \%$ y del $22 \%$ respectivamente. Y en la franja baja del diálogo se haya el diario Le Monde con un 5,71\% de mensajes de diálogo.

¿Qué relación existe entre los mensajes de diálogo respecto a los que se sitúan en las actitudes de refuerzo de opiniones previas y los que se critican mensajes publicados con anterioridad? Mayoritariamente los mensajes de diálogo, como los mensajes 
que respondían a una retórica de la participación, muestran punto de vista críticos con mensajes anteriores y actitudes contrarias a los mensajes publicados. En la mayoría de los diarios analizados la relación entre mensajes de diálogo positivos o negativos se salda a favor de mensajes negativos en una proporción de 3 a 1: por cada mensaje que muestra afinidad con otra aportación, tres muestran desacuerdo. Sólo Le Monde y $A B C$ equilibran los mensajes de descuerdo y los de acuerdo (66,67\% y $54,55 \%$ respectivamente de mensajes de diálogo que muestran desacuerdo). Esta era también la regla general por lo que respecta al estudio sobre las cartas al director. En el análisis de la sección de cartas al director, el 76,59\% de las cartas de diálogo mostraban acuerdo y el 23,40\% mostraban desacuerdo.

Cabe en este punto recordar que los mensajes de diálogo se agruparon en siete categorías en función de la actitud que mostraran en el supuesto diálogo con otros lectores. Estas siete categorías correspondían a "ayuda, apoyo, refuerzo de una opinión afín y resolución de conflicto" por lo que respecta a los mensajes que mostraban acuerdo y a "aclaración, disconformidad o descalificación" respecto a los mensajes que mostraban desacuerdo. Este estudio muestra que se han producido cambios significativos respecto al reparto de los mensajes de diálogo entre estas siete categorías. Entre las aportaciones de acuerdo en los diarios digitales los mensajes de apoyo son en general mayoritarios (56,95\%), mientras que en la sección de cartas eran mayoritarios entre los mensajes de acuerdo los que reforzaban una opinión afín $(81,81 \%)$. Eso significa que en los diarios digitales las respuestas a otros lectores están más contrastadas y se toma más partido a favor de la opinión expresada previamente por otro lector.

Por otro lado, destaca el aumento del número de mensajes descalificadores en la prensa digital europea. Y no sólo eso, sino que los resultados muestran una especificidad de la prensa digital española. Los tres diarios españoles analizados se muestran como los únicos en los que el porcentaje de mensajes descalificadores e insultantes es muy significativo respecto a los mensajes de diálogo que muestran desacuerdo. Las cifras son las siguientes: La Vanguardia publica un $48,78 \%$ de mensajes descalificadores; El País publica un 34,33\% y $A B C$ publica un $20 \%$. Para el resto de diarios, franceses e ingleses, el número de mensajes de descalificación y los porcentajes resultantes son residuales: el 8,93\% en Le Figaro; el 2,53\% en The Guardian y ningún mensaje descalificador en Le Monde y en The Times. Es decir, mientras los mensajes descalificadores alcanzar un 34,36\% en la prensa española, sólo suponen el 4,46\% de los mensajes de diálogo que muestran desacuerdo de la prensa francesa y el 1,26\% de los de la prensa inglesa.

\section{Discusión: las nuevas reglas de la participación}

Los resultados expuestos en este artículo muestran que las reglas que regían la publicación de las cartas de los lectores en la prensa tradicional se han modificado absolutamente en la publicación de mensajes de los lectores en la prensa digital. De entrada, ha cambiado el agente que selecciona y controla los textos publicados. En el paradigma predigital, esta función la poseía el periodista responsable de la sección de participación. En la prensa digital esta función está en poder de los propios lectores, con 
la aquiescencia de los responsables del diario. Las reglas que aplican los periodistas que controlan la sección de cartas al director y las reglas que permiten la publicación de los mensajes de los lectores en los espacios de participación digital se ha mostrado que son realmente distintas.

Frente a la regla de la identidad, piedra de toque de cualquier sección seria de cartas al director, se ha impuesto la regla del anonimato. Esta regla permite que los mensajes vayan firmados con pseudónimos (nicks) que hacen inverificable la identidad del autor del texto. En este sentido se ha visto que los autores de los mensajes publicados en la prensa francesa e inglesa, aunque los firmen con nicks, pretenden mantener unos visos de verosimilitud identificándose con una estructura de nombre y apellido. En cambio, en la prensa española los apodos usados por los remitentes de los mensajes resultan muy poco identificativos.

La regla de la relevancia se centra en el debate político. Este interés por la política nacional sitúa en segundo término temas de las secciones de Sociedad y de Internacional, que suscitaban abundantes cartas en la prensa tradicional. El debate político, además, se caracteriza por el enfrentamiento entre lectores. En la prensa digital los participantes contrastan sus posiciones. En este sentido, la investigación ha mostrado que aumentan los mensajes de apoyo a otro mensaje y también de enfrentamiento con otro lector, algunas veces con un tono descalificador.

La regla de la brevedad se exagera en los espacios de participación de la prensa digital. En general la longitud de los textos de las cartas al director se ha reducido un $67 \%$ en los mensajes de la prensa digital: se ha pasado de una media de 157 palabras por carta a 57 palabras por mensaje. Esta "ultrabrevedad" de los mensajes puede dificultar los debates con argumentos, tal como indicaba WAHL-JORGENSEN (2002), y puede hacer que la calidad de los debates descienda, como apuntaba FRIEDLAND (2010).

La regla del entretenimiento ha pasado de centrarse en contar temas que son serios para los participantes y que provocan la curiosidad del lector a focalizarse en el enfrentamiento ideológico e, incluso, personal. El entretenimiento se vehicula a través del enfrentamiento de lectores, lo que provoca, sobre todo en la prensa digital española, la desaparición de la regla de la civilidad. En su lugar impera una nueva regla, la de la descortesía y la descalificación: en la prensa digital española el 34,37\% de los mensajes de diálogo que muestran desacuerdo resultan insultantes para otro lector, frente al $4,47 \%$ de la prensa francesa y el $1,26 \%$ de la prensa inglesa.

\section{Referencias bibliográficas}

ABRIL VARGAS, Natividad (1999): Periodismo de opinión: claves de la retórica periodística. Madrid, Síntesis.

ALLAN, Stuart \& THORSEN, Einar (2009): Citizen Journalism, New York, Peter Lang.

ARIAS, Juan (1996): “¿Más espacio para los lectores?, en El País, 30 de junio, p. 16. ARMAÑANZAS, Emy y DÍAZ NOCI, Javier (1996): Géneros de opinión. Periodismo y argumentación. Bilbao, Universidad del País Vasco. 
ARMENTIA, José Ignacio; CAMINOS, José María; ELEXGARAY, Jon; MARÍN, Flora; MERCHÁN, Iker (2000): El diario digital. Barcelona, Bosch.

BARLOW, Aaron (2010): "The Citizen Journalist as Gatekeeper: A Critical Evolution", en ROSENBERRY, Jack; ST. JOHN, Burton. Public Journalism 2.0, New York, Routledge, pp. 45-55.

BAUMAN, Zygmund (2000): Liquid Modernity, Cambridge, Polity Press.

BERGSTRÖM, Annika (2008): "The reluctant audience: online participation in the Swedish journalistic context, Westminster Papers in Communication and Culture, vol. 5 (2), pp. 60-80.

BOWMAN, Shayne \& WILLIS, Chris (2003): "We Media. How audiences are shaping the future of news and information". [En línea]. NDG. July 2003. http://www.ndn.org [Consulta: septiembre 2003].

BROWN, Gillian \& YULE, George (1993): Análisis del discurso, Madrid, Visor.

BRUNS, Axel (2005): Gatewatching: Collaborative online news production, New York, Peter Lang.

BUCETA FACORRO, Luis (1992): Fundamentos psicosociales de la información, Madrid, Editorial Centro de Estudios Ramón Areces.

CARPENTER, Serena (2008): "How online citizen journalism publicacions and online newspapers utilize the objectivity standard and rely on external sources", Journalism and Mass Communication Quarterly, 85 (3), pp. 531-548.

CASSANY, Daniel (1993): La cuina de l'escriptura, Barcelona, Empúries.

CLARK, Diane (1990): “Op-ed pages often take themselves too seriously", The Masthead, 42 (2), pp 6-7

DE BEAUGRANDE, Robert-Alain y DRESSLER, Wolfgang Ulrich (1997): Introducción a la lingüistica del texto, Barcelona, Ariel.

DEL HOYO, Jaime (2001): La presencia del lector en la prensa: las cartas al director en cuatro diarios de Sevilla, Tesis, Sevilla, Universidad de Sevilla.

DESLANDES, Ghislain; FONNET, Laurent; GODBERT, Antoine (2009): "Éthique des médias sociaux et économie de la participation: Vers une nouvelle approche éditoriale? Une étude comparative", Global Media Journal (Canadian Edition), volume 2 (1), pp. 41-61.

DEUZE, Mark (2009): "Journalism, Citizenship, and Digital Culture", en PAPACHARISSI, Zizi, Journalism and Citizenship, New York, Routledge, pp. 15-28.

DEUZE, Mark; BRUNS, Axel; NEUBERGER, Christoph (2007): "Preparing for an age of participatory news", Journalism Practice, 1 (3), pp. 322-338.

DOMINGO, David; QUANDT, Thorsten ; HEINONEN, Ari; PAULUSSEN, Steve; SINGER, Jane B.; VUJNOVIC, Marina (2008): "Participatory journalism practices in the media and beyond: an International comparative study of initiatives in online newspapers", Journalism Practice, 2 (3), pp. 326-342. 
DUPRE, Michael E.; MACKEY, David A. (2000): "Newspaper letters and phonemail to the editor: a comparison of reader input". Presented at the Mass Communication and Society Division, Association for Education in Journalism and Mass Communication Annual Convention, August, Phoenix.

FOIX, Lluis (1997): “¿Cómo se escogen las cartas al director en 'La Vanguardia’?”. El Ciervo [Barcelona], núm. 555, pp. 21-22.

FORTUNATI, Leopoldina; SARRICA, Mauro; O'SULLIVAN, John; BALCYTIENE, Aukse; HARRO-LOIT, Halliki; MACGREGOR, Phil; ROUSSOU, Nayia; SALAVERRÍA, Ramón; DE LUCA, Federico (2009): "The Influence of the Internet on European Journalism", Journal of Computer-Mediated Communication, 14, pp. 928-963

FRAISSE, Paul y MEILI, Richard (1967): Psicología de las actitudes, Buenos Aires, Proteo.

FRIEDLAND, Lewis A. (2010): "Open Source Interview: The Evolution of Public Journalism", en ROSENBERRY, Jack; ST. JOHN, Burton, Public Journalism 2.0, New York, Routledge, pp. 56-65.

GARRIDO MEDINA, Joaquín (1997): Estilo y texto en la lengua, Madrid, Gredos.

GILLMOR, Dan (2004): We the media. Sebastopol, O’Reilly.

GOMIS, Lorenzo (1989): Teoria del gèneres periodístics, Barcelona, Generalitat de Catalunya. Centre d'Investigació de la Comunicació.

GOMIS, Lorenzo (1991a): "Les cartes dels lectors com a barem de la receptivitat periodística”, Periodística [Barcelona], núm. 4, pp. 89-93.

GOMIS, Lorenzo (1991b): Teoría del periodismo. Cómo se forma el presente, Barcelona, Paidós.

GOMIS, Lorenzo (1994): "Persuadir la gent de que passen coses interessants", Periodística núm. 7, pp. 59-64.

GUILLÉN, Claudio (1998): Múltiples moradas, Barcelona, Tusquets, 1998.

HAAS, Tanni (2010): “Open Source Interview: Online Dialogue, Public Life and Citizen Journalism”, en ROSENBERRY, Jack; ST. JOHN, Burton, Public Journalism 2.0, New York, Routledge, pp. 126-132.

HYNDS, Ernest C. (1976): "Editorial pages are taking stands, providing forums", Journalism Quarterly 53, 3, pp. 532-535.

HYNDS, Ernest C. (1991): "Editorial page editors discuss use of letters", Newspaper Research Journal, 13 (1), pp. 124-136.

KAPOOR, Suraj \& BOTAN, C. (1992): "Studies compare how editors use letters", The Masthead, 44 (1), pp. 5-7.

KAPOOR, Suraj (1995): “Most Papers Receive More Letters”, The Masthead, 17 (2).

KAYSER, Wolfgang Johannes (1985): Interpretación y análisis de la obra literaria, Madrid, Gredos, (4 edición). 
LASICA, Joseph D. (2002): "The Promise of the Daily Me", Online Journalism Review, http:// http://www.ojr.org/ojr/lasica/1017779142.php [Consulta: enero 2010]

MARTIN, Paul S. (2008): "The mass media as centinels: why bad news about issues is good news for participation", Political Communication, 25, pp. 180-193.

MATHESON, Donald (2004): "Weblogs and the Epistemology of the News: Some Trends in Online Journalism", New Media and Society, 6 (4), pp. 443-468.

MERRILL, John C. (1999): “The Global Elite. World's best newspapers reflect political changes". [En línea], IPI Report, $n^{\circ}$ 4. 1999. http://www.freemedia.at/IPIReport4.99/IPIRep4-99_The\%20Global\%20Elites.htm [Consulta: febrero: 2002]

MORÁN TORRES, Esteban (1988): Géneros de periodismo de opinión. Crítica, comentario, columna, editorial, Pamplona, Eunsa.

NEMETH, Neil \& ANDERS, Craig (1999): "The Quest for Credibility Through the Public Dialogue in Correction Boxes, Letters to the Editor and Columns Written by Newspaper Ombudsmen". A Paper Submitted to the Newspaper Division of the Association for Education in Journalism and Mass Communication Annual Convention, New Orleans, Louisiana, August.

NIP, Joyce Y.M. (2010): "Routinization of Charisma: The Institutionalization of Public Journalism Online", en ROSENBERRY, Jack; ST. JOHN, Burton. Public Journalism 2.0, New York, Routledge, pp. 135-148.

NORD, David (1995): "Reading the Newspaper, Strategies and Politics of Reader Response, Chicago 1912-1917", Journal of Communication, 45 (3), p. 67.

NÚÑEZ LADEVÉZE, Luis (1993): Teoría y práctica de la construcción del texto. Barcelona, Ariel.

PALACIOS, Marcos (2010): "Positioning yet another idea under the glocalisation umbrella: Reader participation and audience communities as market strategies in globalised online journalism", Communicatio, 36 (2), pp. 276-287.

PAPACHARISSI, Zizi (2009): Journalism and Citizenship, New York, Routledge.

PASTOR, Lluís (2006): "Un análisis de las cartas al director en diarios de referencia internacional", Comunicación y Sociedad, vol. 19, núm. 1, 129-158.

PASTOR, Lluís (2010): Teoría de las cartas al director. La gestión periodística del público 1, Barcelona, Editorial UOC.

QUINN, Gary \& TRENCH, Brian (2010): "Online News Media and Their Audiences", Multimedia Content in the Digital Age, Mudia. http://www.mudia.org [Consulta: junio 2010]

ROSENBERRY, Jack \& ST. JOHN, Burton (2010): "Introduction: Public Journalism Values in an Age of Media Fragmentation", en ROSENBERRY, Jack; ST. JOHN, Burton, Public Journalism 2.0, New York, Routledge.

RUIZ, Carlos; MASIP, Pere; MICÓ, Josep Lluís; DÍAZ-NOCI, Javier; DOMINGO, David (2010): “Conversación 2.0. y democracia. Análisis de los comentarios de los 
lectores en la prensa digital catalana”, Comunicación y sociedad, vol. 23, núm. 2, pp. 7-39.

SALAVERRÍA, Ramón (1997): “Aproximación a los orígenes de la preceptiva sobre escritura periodística (1840-1940), en Comunicación y sociedad, Pamplona: Universidad de Navarra, pp. 61-95.

SANTAMARÍA, Luisa (1990): El comentario periodístico. Los géneros persuasivos, Madrid, Paraninfo.

SCHAFFER, Jan (2010): “Open Source Interview: Civic and Citizen Journalism's Distinctions", en ROSENBERRY, Jack; ST. JOHN, Burton. Public Journalism 2.0, New York, Routledge, pp. 176-182.

SERAFINI, María Teresa (1994): Cómo se escribe, Barcelona, Paidós.

SINGER, James B. \& ASHMAN, Ian (2009): "User-Generated Content and Journalistic Values", en ALLAN, Stuart \& THORSEN, Einar. Citizen Journalism, New York, Peter Lang, pp. 233-242.

THORNTON, Brian (1996): "The Shrinking Debate over Journalistic Standards: Where Have all the Letters Gone?" A paper presented to the Magazine Division, as part of the Association for Education in Journalism and Mass Communication Annual Conference, Anaheim, California, August.

THORNTON, Brian (1998): "Reviewing the record: What Magazine Letters to the Editor Said about Journalism in 1962, 1972, 1982 and 1992". A paper accepted for presentation to the Magazine Division as part of the AEJMC Annual Conference in Baltimore, August.

VAN DIJK, Teun A. (1983): La ciencia del texto, Barcelona, Paidós.

VAN DIJK, Teun A. (1995): Estructuras y funciones del discurso ( $9^{\mathrm{a}}$ edición), Madrid, Siglo Veintiuno.

WAHL-JORGENSEN, Karin (2002): "Understanding the Conditions for Public Discourse: Four Rules for Selecting Letters to the Editor", Journalism Studies 3 (1), pp. 69-82.

YAROS, Ronald A. (2009): "Producing Citizen Journalism or Producing Journalism for Citizens: A New Multimedia Model to Enhance Understanding of Complex News", en PAPACHARISSI, Zizi. Journalism and Citizenship, New York, Routledge, pp. 71-90. 